\title{
A novel type of wearable dual-band antenna based on coplanar waveguide feeding for wearable wireless communications
}

\author{
ZHENGRUi HE, JiE JIN
}

School of Electronic Information Engineering, Tianjin University, China

\begin{abstract}
A flexible and compact coplanar waveguide feed (CPW-fed) wearable antenna is introduced for wireless wearable communications applications at the industrial scientific medical (ISM) band. The proposed antenna consists of copper, which is used as the radiation patch and ground planes printed on the same side of polyimide flexible substrate. The overall size of the antenna is $30 \mathrm{~mm}$ $\times 28 \mathrm{~mm} \times 0.08 \mathrm{~mm}$, the results show that the antenna can transmit and receive signals in two frequency bands of $1.89-2.67 \mathrm{GHz}$ and $3.02-3.23 \mathrm{GHz}$, in which radiating properties are characterized and agree well with the simulation results. The antenna is bent in different directions to further investigate the reflection coefficient and corresponding effect on the antenna under bending. The center frequency of the antenna is slightly shifted towards higher and lower frequencies when antenna is bent in $X$-axis and $Y$-axis, respectively. Furthermore, the wearability of the antenna is verified when the antenna is placed on different parts of the human body such as wrist and chest. Hence, the proposed flexible antenna is a suitable candidate for wearable wireless communication applications.
\end{abstract}

Keywords: wearable antenna, dual-band antenna, CPW-feed, metasurface.

\section{Introduction}

In recent years, with the development of wireless body-area network (WBAN) and wearable electronics devices, investigations on the body centric wireless networks have drawn significant attention [1, 2]. WBAN is centered on the human body and in vitro communication equipment into a network. With the help of the WBAN, the medicine, personal identification, navigation or entertainment will become better [3] . However, due to the particularity of the WBAN, common antennas cannot work very well. So studying the wearable antenna is the urgent affair. The $2.4 \mathrm{GHz}$ frequency band centered at $2.45 \mathrm{GHz}$ is the common industrial scientific medical (ISM) band for all countries and WLAN, Bluetooth, ZigBee and other wireless networks can work in the $2.4 \mathrm{GHz}$ band. Hence, the $2.4 \mathrm{GHz}$ band is the best choice for WBAN.

Compared with the traditional rigid antenna, flexible substrate materials are critical to the study of wearable antennas [4]. In order to develop wireless communication systems that can be integrated into flexible materials, the requirements for flexible antennas 
and flexible passive devices are very stringent [ [5]. The radiation patch of antennas is fabricated based on highly conductive and stretchable material (e.g., silver nanowires [] $]$, graphene [ $\underline{7}]$, and fluid metal [ $\underline{8}]$ ), which is printed on flexible substrate, including polyethylene terephthalate (PET) [9] , polydimethylsiloxane (PDMS) [10], polyimide (PI) [11, 12], paper and textiles [13], etc. In addition, antennas with flexibility and conformability have recently been proposed for the wearable wireless communication systems [14].

In order to realize the flexible wearable function and improve the utilization of antenna, a wearable dual-frequency flexible antenna based on polyimide material is designed in this paper. Through the coplanar waveguide feeding mode and the use of PI materials, the antenna radiation patch and ground plane are integrated on the same side of the dielectric substrate, so that the antenna radiation patch can deform with the deformation of the dielectric substrate in a complex environment, and can maintain normal working performance. In addition, through constant modification and optimization of the shape and size of the radiation patch and ground plane, the antenna can transmit and receive signals in two frequency bands of $1.89-2.67 \mathrm{GHz}$ and $3.02-3.23 \mathrm{GHz}$, which effectively reduces the size of wearable devices. The simulation results show that the designed antenna has a return loss of less than $-10 \mathrm{~dB}$, a voltage standing wave ratio of less than 2, and a good impedance matching degree in the two operating frequency bands. Meanwhile, the performance of $E$-plane and $H$-plane of the radiation pattern is guaranteed, which meets the requirements of flexible wearable and dual-band operation.

\section{Antenna design}

Polyimide (PI), a type of flexible substrate, is widely used in printed electronics, vehicular communications and navigation because of its good stability, resistance to radiation and dielectric properties [11]. However, there is a challenge to improve the properties of wearable antenna for WBAN. In order to achieve miniaturization and better performance, wearable antenna adopts coplanar waveguide feed (CPW-fed) which allows the radiation patch and the ground plane to be located in the same layer of the flexible substrate to achieve parallel or series connection with other microwave devices $[\underline{15}, 16]$. The PI material is chosen for design of the antenna with thickness of $0.08 \mathrm{~mm}$ as the dielectric substrate, dielectric constant of 4.3 , loss tangent of 0.004 , and the radiation patch and ground plane of the antenna are the most commonly used copper material (thickness of $0.5 \mathrm{inch}$ ). Coplanar waveguide feeding structure is adopted, and the ground plane comprises two rectangular patches operated by cutting corners and ring structure, which are printed on the same side of the antenna as the radiation patch with a rectangular gap. The overall size of the antenna is $30 \mathrm{~mm} \times 28 \mathrm{~mm} \times 0.08 \mathrm{~mm}$. The antenna structure is shown in Fig. 1. Antenna with a coplanar waveguide feed mode, the input impedance of $50 \Omega$, good impedance matching is realized. The specific size parameters of the optimized antenna are as follows: $L=30 \mathrm{~mm}, L_{1}=19 \mathrm{~mm}, W=28 \mathrm{~mm}$, $W_{1}=8.6 \mathrm{~mm}, L_{2}=11.4 \mathrm{~mm}, W_{2}=9 \mathrm{~mm}, L_{3}=3 \mathrm{~mm}, W_{3}=4.6 \mathrm{~mm}, L_{4}=7.4 \mathrm{~mm}$, 


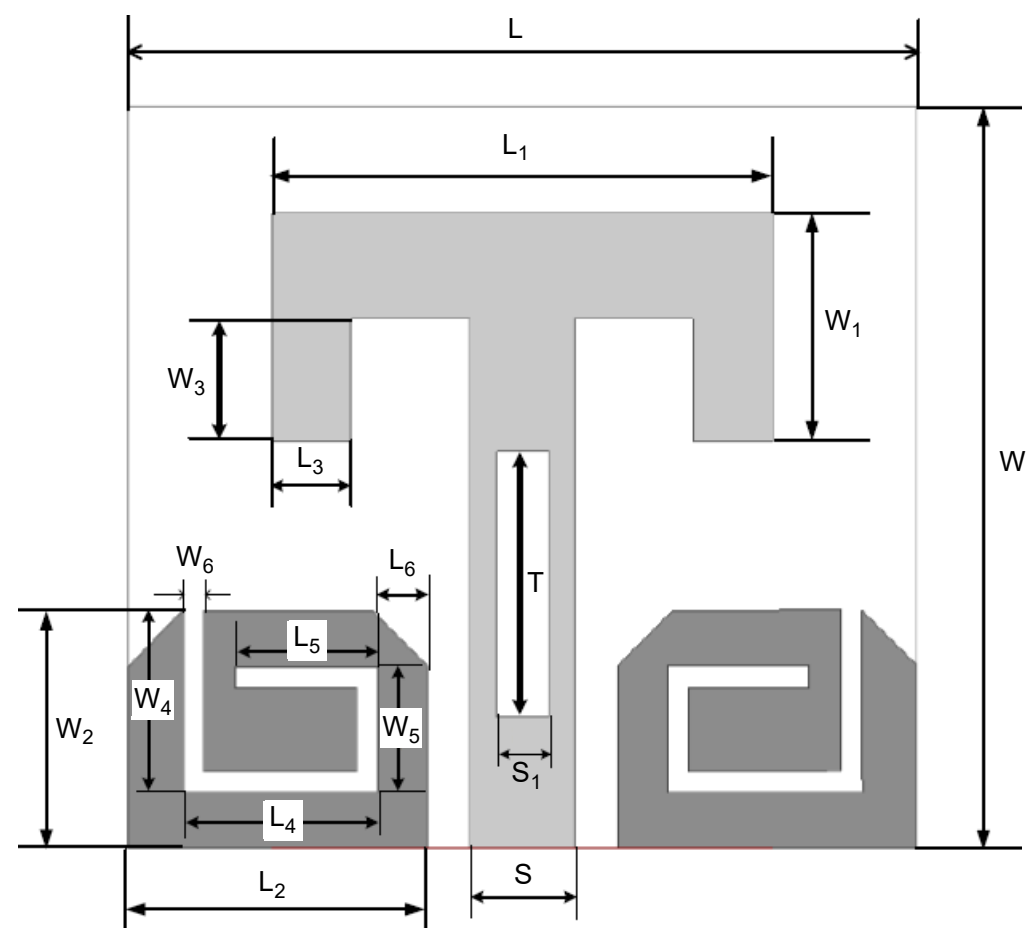

Fig. 1. Dimension diagram of dual-band flexible antenna structure.

$L_{5}=5.4 \mathrm{~mm}, W_{5}=4.6 \mathrm{~mm}, L_{6}=2.1 \mathrm{~mm}, W_{5}=0.8 \mathrm{~mm}, S=4 \mathrm{~mm}, S_{1}=2 \mathrm{~mm}, T=$ $=10 \mathrm{~mm}$, and the thickness of the dielectric substrate $H=0.08 \mathrm{~mm}$.

A single layer antenna fed by a coplanar waveguide is proposed. To achieve a dual -band, the antenna introduces ring structure on patch and slot on the ground plane. Simulations based on commercial software Ansys HFSS and experiments are both con-

a

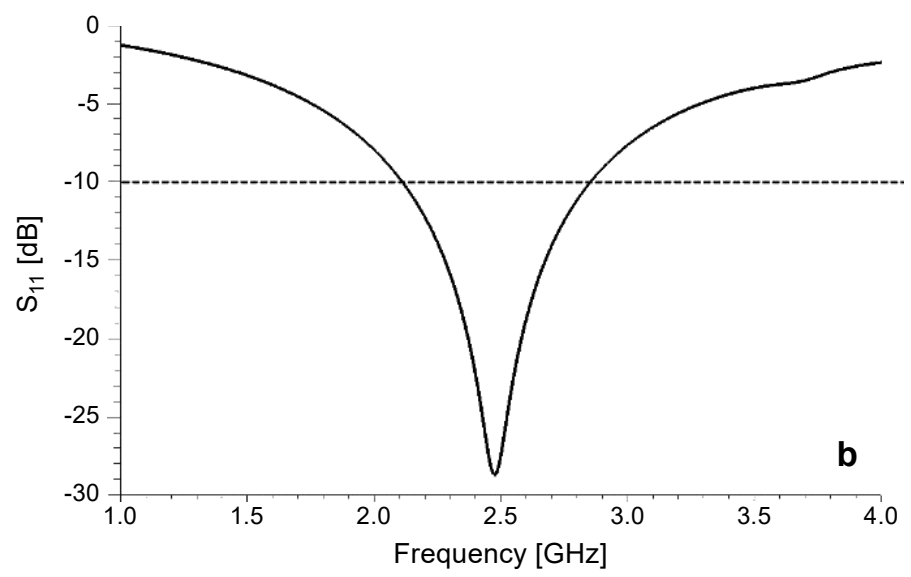

Fig. 2. Original antenna (a) and its return loss variation with frequency curve (b). 
ducted to verify the performances of the proposed antenna. Figure $2 \mathbf{a}$ is the unmodified and optimized single-band flexible antenna, whose return loss varies with frequency as shown in Fig. 2b. The optimal resonant frequency of the antenna is $2.48 \mathrm{GHz}$ and $S_{11}$ is $-28.70 \mathrm{~dB}$. In the $2.11-2.85 \mathrm{GHz}$ band, the return loss is less than $-10 \mathrm{~dB}$ and the absolute bandwidth is $0.74 \mathrm{GHz}$.

Figure $3 \mathbf{a}$ is the antenna with the ground plane cut on both sides to form the isosceles right triangle with $2.10 \mathrm{~mm}$ side length, and with the metal line in the middle changed. The return loss changes with the frequency, as shown in Fig. 3b. The shape and size of the radiation patch did not change, so the resonant point of the antenna did not change.

a

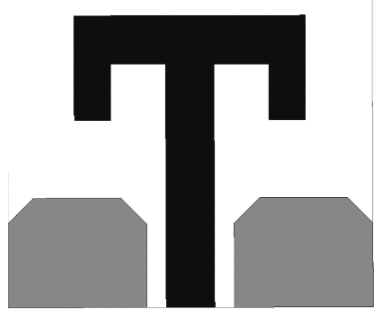

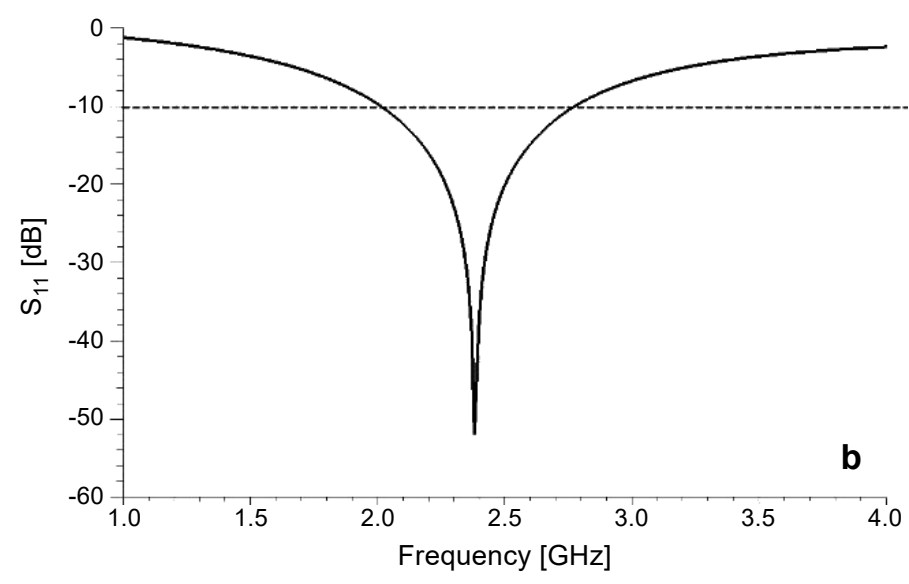

Fig. 3. Antenna after corner cutting of the ground plane (a) and its return loss variation with frequency curve (b).

a

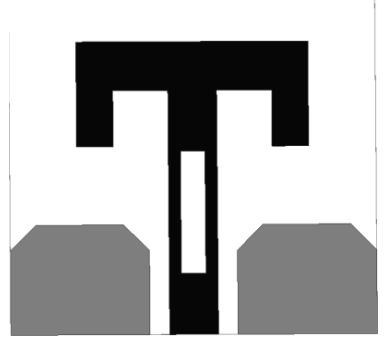

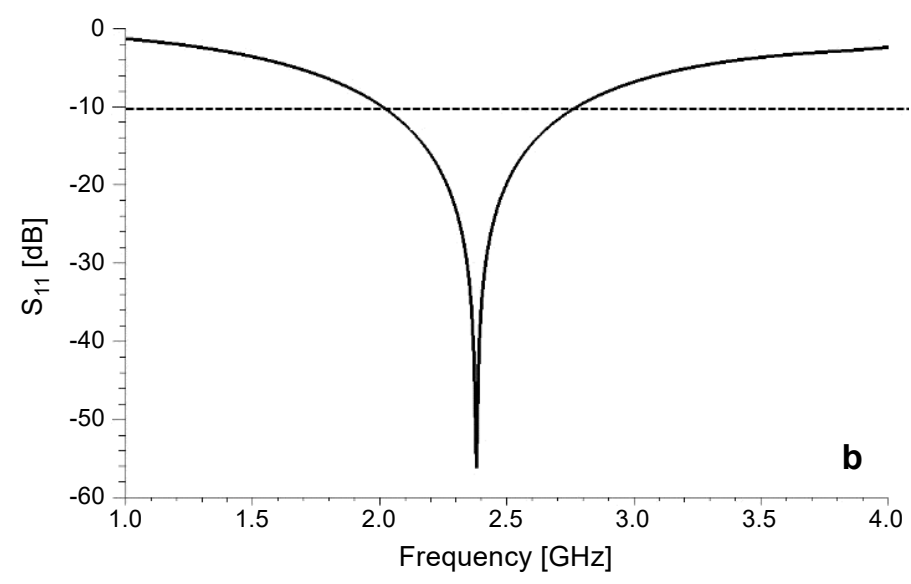

Fig. 4. Antenna after the slit of the radiation patch introduced (a) and its return loss changing with frequency (b). 
However, the angle cutting behavior of the ground plane deepens the resonance degree, so at the resonance frequency of $2.48 \mathrm{GHz}, S_{11}$ deepens to $-51.97 \mathrm{~dB}$. In addition, by further optimizing the antenna size, the working bandwidth of the antenna is also widened to $0.77 \mathrm{GHz}$, working in $2.01-2.78 \mathrm{GHz}$ frequency band, which greatly improves the performance of the antenna in this frequency band.

Figure $4 \mathbf{a}$ is the single-band flexible antenna after the radiation patch is introduced into the slot structure based on the angle cutting operation of the two ground planes. The return loss varies with the frequency, as shown in Fig. $4 \mathbf{b}$. Through the slit of the radiation patch, the antenna can also work normally in $2.01-2.79 \mathrm{GHz}$ frequency band, and the return loss reaches $-56.20 \mathrm{~dB}$ at $2.38 \mathrm{GHz}$, which can carry out signal radiation, thus turning the antenna into a dual-frequency antenna.

The antenna optimized by introducing symmetrical ring structure to two ground planes is shown in Fig. 5a, and the return loss varies with the frequency, as shown in Fig. 5b. By introducing a symmetrical ring structure on the two ground planes of the antenna, the antenna can double resonance and achieve the effect of a dual-frequency band. It can be seen from Fig. 5b that the introduction of symmetrical ring structure enables the antenna to work normally in the two frequency bands of $1.89-2.67 \mathrm{GHz}$ and $3.02-3.23 \mathrm{GHz}$. At the first resonant frequency of $2.25 \mathrm{GHz}$, the return loss is $-18.41 \mathrm{~dB}$, while at the second resonant point of $3.16 \mathrm{GHz}$, the return loss is $-19.74 \mathrm{~dB}$, the bandwidth is 0.78 and $0.21 \mathrm{GHz}$, respectively, and the total bandwidth is $0.99 \mathrm{GHz}$, greatly improving the performance. Figure 6 shows the gain diagram of plane $E$ and plane $H$ of the antenna at $2.45 \mathrm{GHz}$.

Figure 7 presents the radiation patterns of the antenna at different frequency points. Figure $7 \mathbf{a}$ shows the resonance at point $2.25 \mathrm{GHz}$ radiation pattern in the $E$ and $H$ planes, while Fig. $7 \mathbf{b}$ shows a resonance at point $3.16 \mathrm{GHz}$ in $E$ and $H$ planes of radiation pat-

a

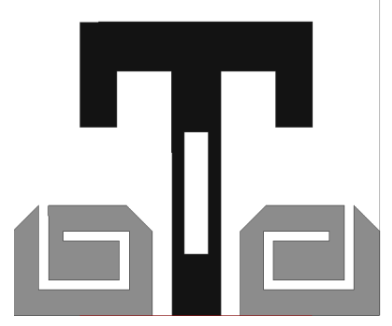

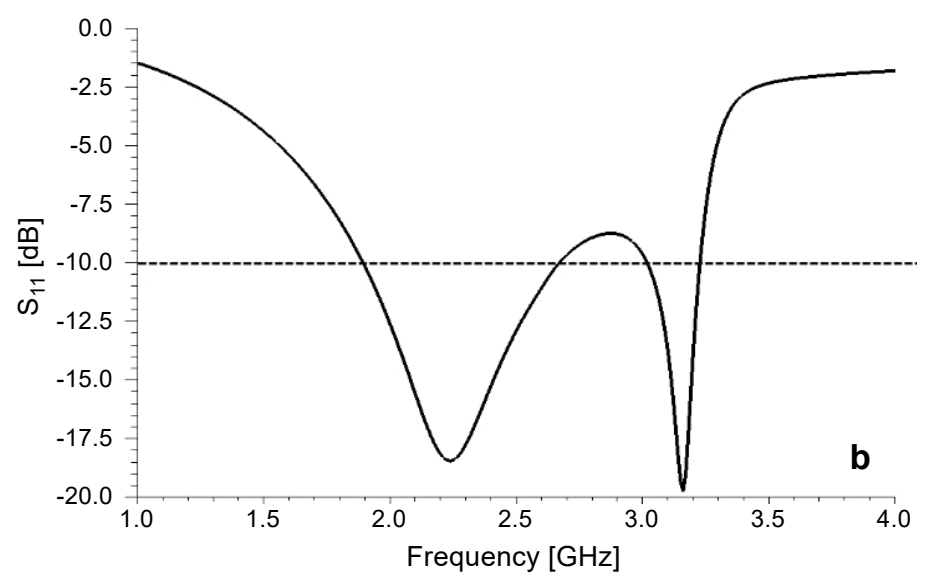

Fig. 5. Dual-frequency band antenna with symmetrical ring structure (a) and its return loss curve with frequency variation $(\mathbf{b})$. 


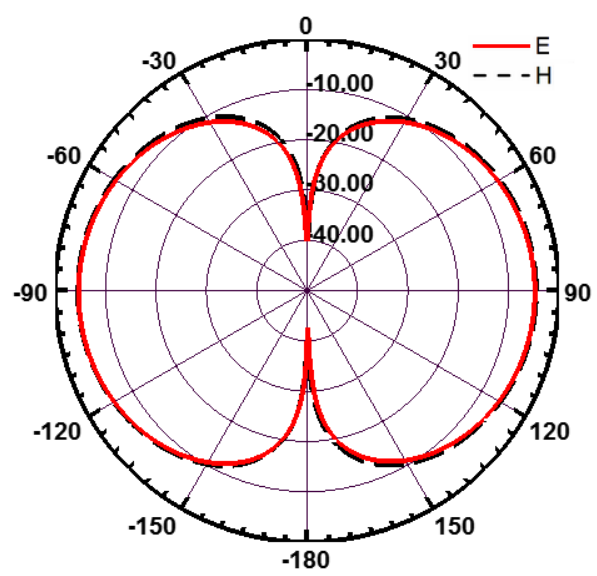

Fig. 6. Gain of the dual-band flexible antenna.
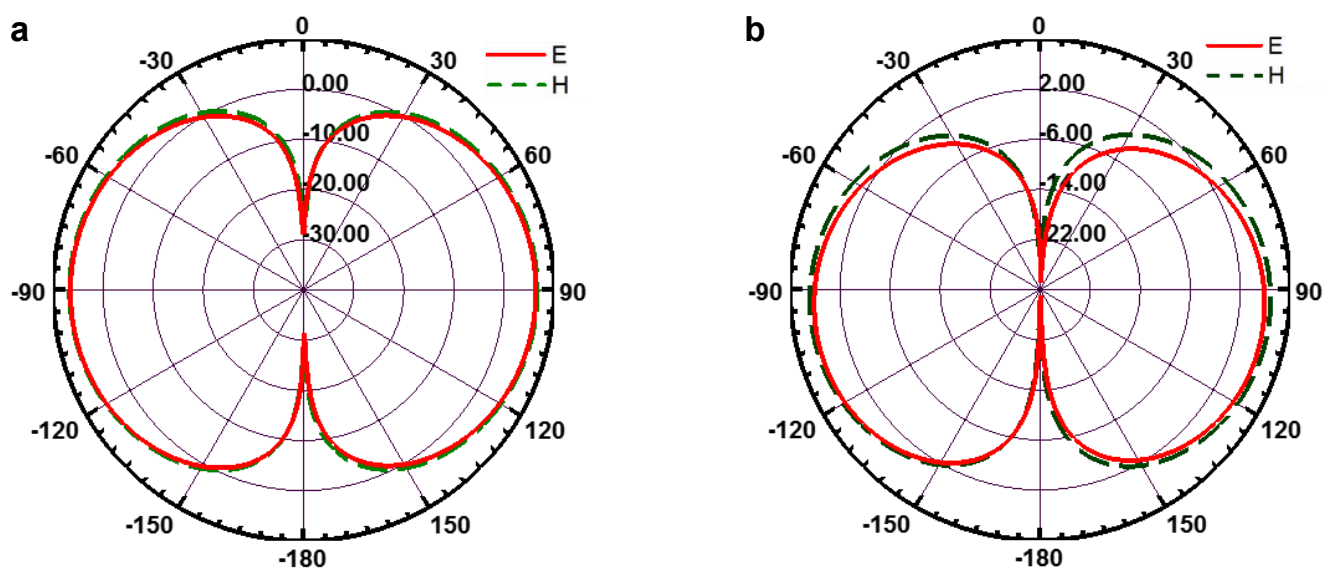

Fig. 7. Radiation pattern of the antenna at different frequencies: $2.25 \mathrm{GHz}(\mathbf{a})$, and $3.16 \mathrm{GHz}(\mathbf{b})$.

tern. Two resonant points can be seen, the dual-band with flexible antenna radiation patterns are of approximate "eight" shape, and present a stable similar radiation characteristics.

Figure 8 is the voltage standing wave ratio (VSWR) curve diagram of the dual-band flexible antenna. It can be seen that in $1.86-2.73 \mathrm{GHz}$ and $2.99-3.23 \mathrm{GHz}$ bands, the VSWR $<2$ can completely cover the two working bands and meet the design requirements.

The surface current distribution of the proposed antenna at 2.25 and $3.16 \mathrm{GHz}$ is shown in Fig. 9. It can be seen from the figure that the surface current is mainly distributed in the spiral structure of the ground, the gap of the patch and the feeder. By controlling the size parameters of these parts, the coupling degree can be affected, then the impedance matching degree can be affected; the impedance matching optimization is realized after optimization. 


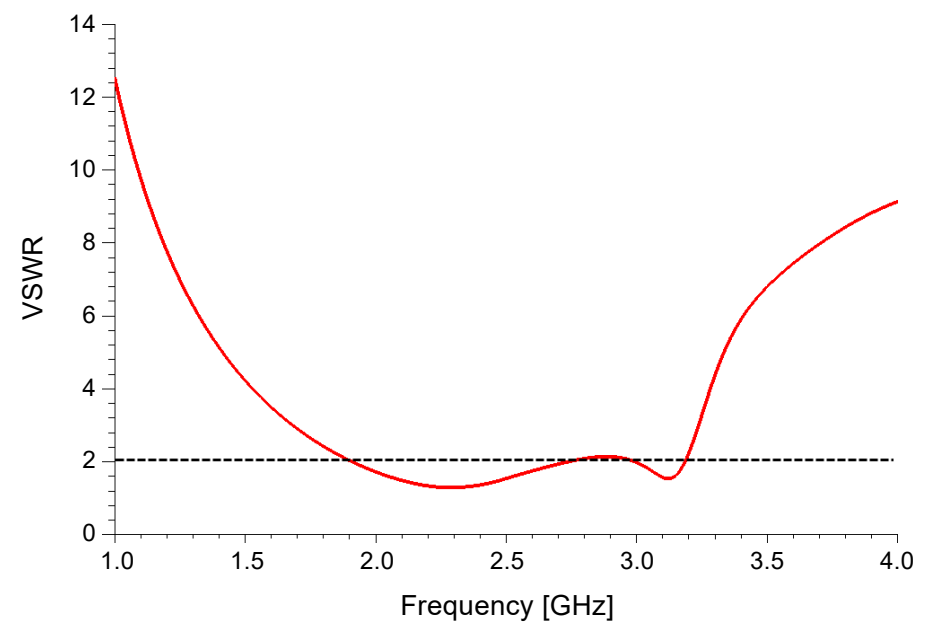

Fig. 8. VSWR of the dual-band flexible antenna.
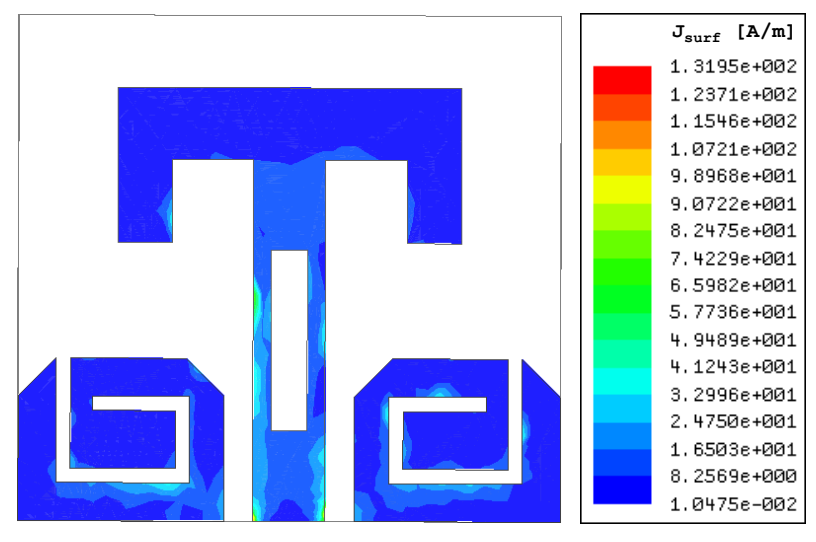

a

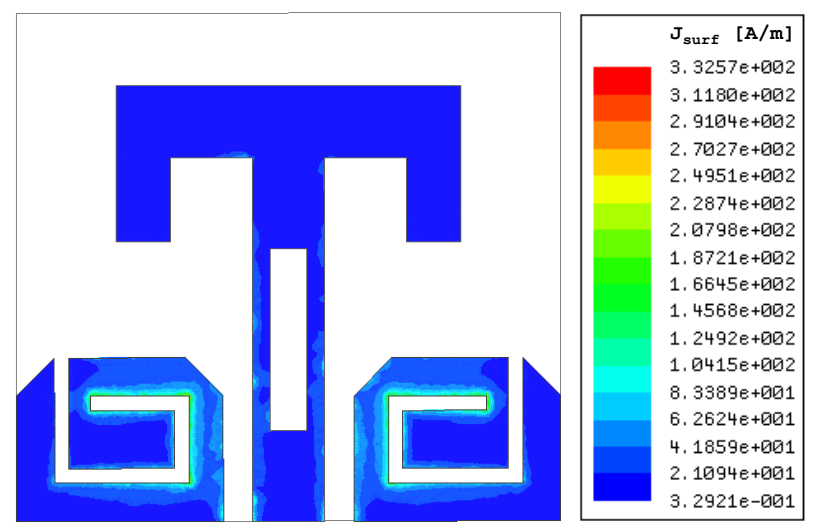

b

Fig. 9. The surface current distribution of the proposed antenna: $f=2.25 \mathrm{GHz}(\mathbf{a})$, and $f=3.16 \mathrm{GHz}(\mathbf{b})$. 


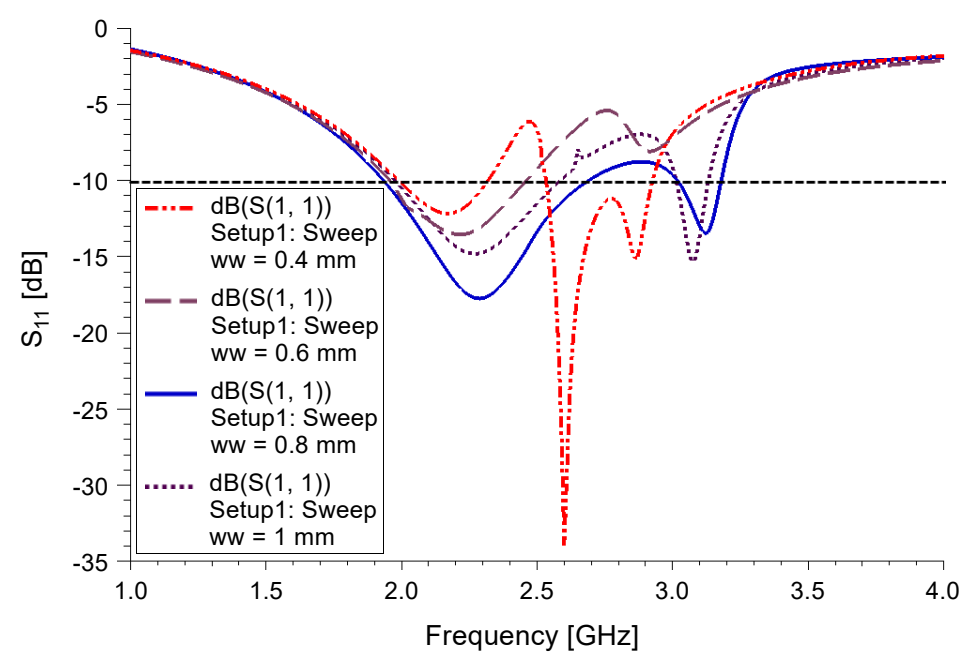

Fig. 10. Curve of $S_{11}$ changing with frequency under different gap widths of ww for symmetrical ring structure of antenna.

Figure 10 shows the variation curve of $S_{11}$ with frequency when the gap widths of symmetrical ring structure with different values is introduced into the antenna ground plane. When $\mathrm{ww}=0.6 \mathrm{~mm}$, the antenna has only one working frequency band; when ww changes from 0.4 to $1.0 \mathrm{~mm}$, the first resonant frequency point shifts to the right, and the absolute bandwidth of both operating bands is improved, the antenna realizes dual band. Therefore, $w w=0.8 \mathrm{~mm}$ is selected to realize the dual-band antenna.

\section{Experimental results and discussion}

The proposed antenna is fabricated and measured. The prototype of the proposed antenna is shown in Fig. 11. The overall size is $30 \mathrm{~mm} \times 28 \mathrm{~mm} \times 0.08 \mathrm{~mm}$, which is similar

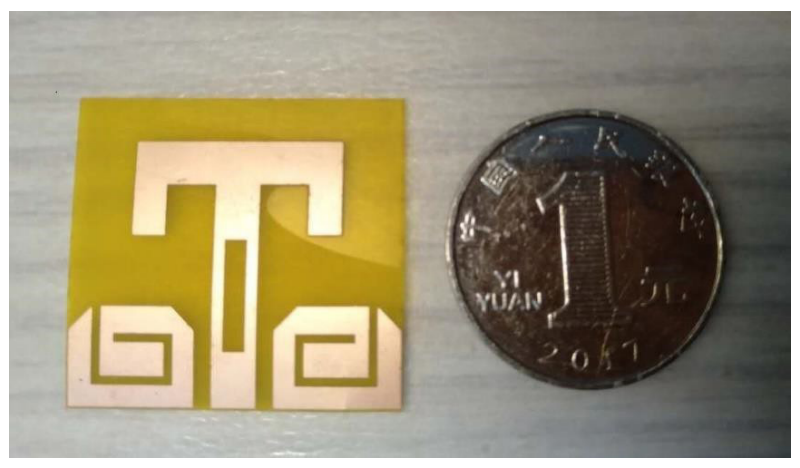

Fig. 11. Physical picture of antenna. 


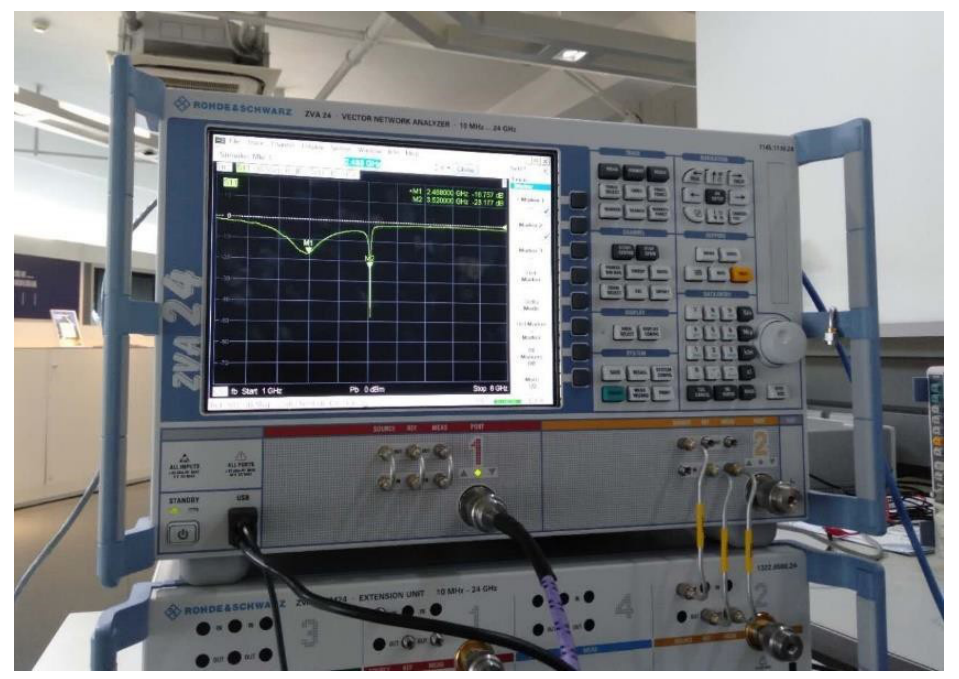

Fig. 12. Test instrument and test environment.

to the size of a one-yuan coin. The medium substrate adopted is flexible material PI, which has great flexibility and heat resistance, so that the antenna can recover after deformation. The thickness of the proposed antenna is $0.08 \mathrm{~mm}$. Figure 12 shows the test environment and the instruments used. The vector network analyzer used in the test is R\&S ZVA24. The test results are clearly visible in the picture. The reflection coefficient $S_{11}$ of the flexible CPW-fed antenna is measured, and the measured and simulated results are revealed in Fig. 12.

Figure 13 is the comparison curve of the simulation and measurement of $S_{11}$, and it can be seen that the results are basically consistent. Compared with the simulated results, the test results of two resonant frequencies are slightly shifted to the right by

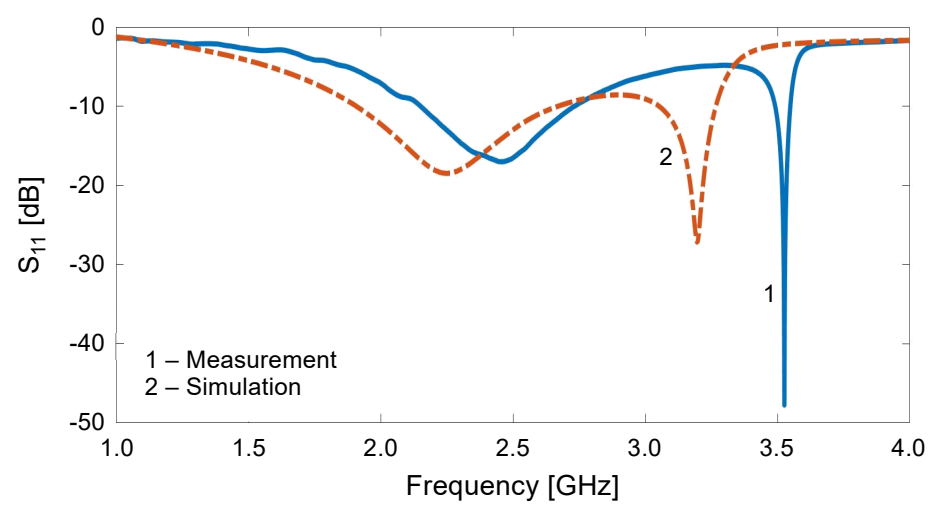

Fig. 13. Comparison diagram of actual measurement and simulation of antenna $S_{11}$. 


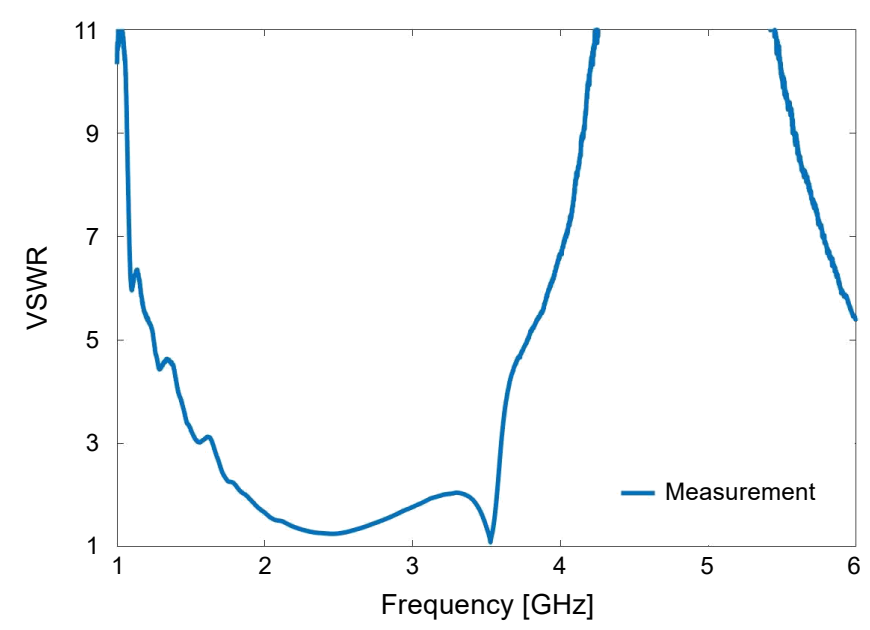

Fig. 14. The measured curve of VSWR.

$0.2 \mathrm{GHz}$, which is caused by manual welding and operation errors. Figure 14 shows a screenshot of the test results of the VSWR directly exported by the vector network analyzer. It can be seen that the condition of VSWR $<2$ is also met in the two working frequency bands of $1.89-2.67 \mathrm{GHz}$ and $3.02-3.23 \mathrm{GHz}$.

Figure 15 indicates that the proposed flexible antenna exhibits a dipole-like pattern in $E$-plane and $H$-plane. Meanwhile, the measured radiation patterns prove that the flexible antenna exhibits well radiation properties, as well as the agreement with the simulated results. The measurement results of the small flexible antenna are more likely to be affected by the manufacturing process, resulting in deviation. In addition, the insufficient welding process of an antenna adapter and other test environments will also interfere with the test results.
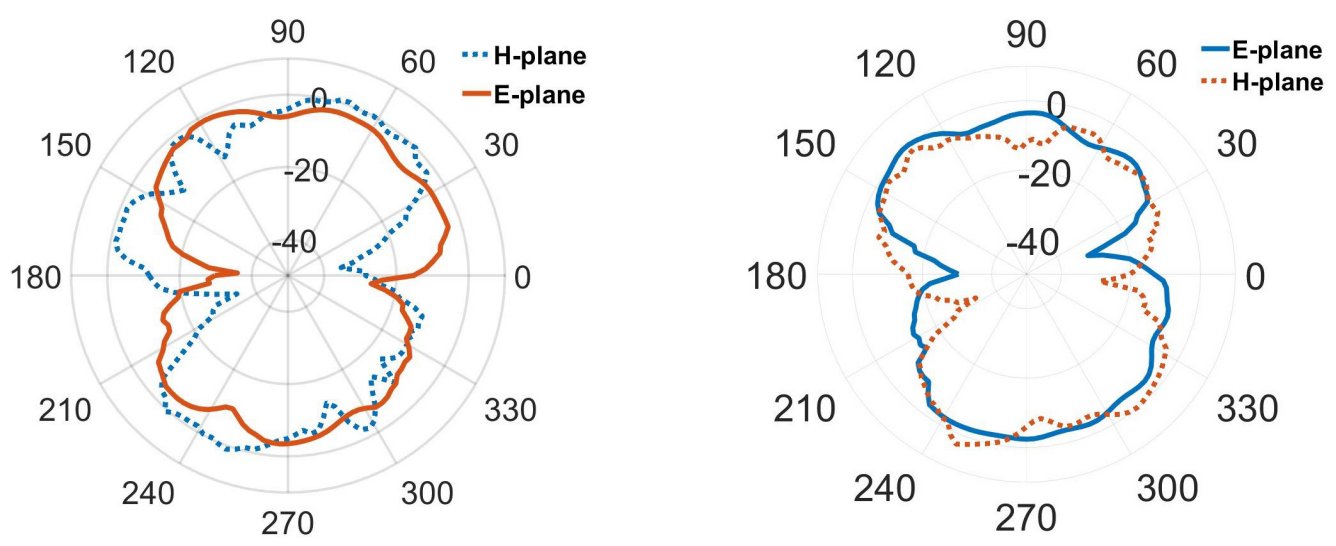

Fig. 15. The measurement result of the proposed antenna at different frequencies: $f=2.25 \mathrm{GHz}(\mathbf{a})$, and $f=3.16 \mathrm{GHz}(\mathbf{b})$. 


\section{Conclusion}

The paper demonstrates a printed flexible CPW-fed antenna which uses PI as the substrate and copper as the radiating element for ISM band. The measurement results of the proposed antenna show that in two frequency bands of $1.89-2.67 \mathrm{GHz}$ and 3.02 $-3.23 \mathrm{GHz}$, which radiating properties are characterized and agree well with the simulation results. The measurement results are in good agreement with the simulation results. Moreover, the proposed antenna meets the engineering requirements of the ISM band and exhibits good radiation characteristics when it is bent in the $X$-axis and $Y$-axis and placed in different parts of the human body. The compact, flexible and highly efficient CPW-fed antennas are easy to fabricate and have omnidirectional radiation characteristics, which is expected to find potential applications in various advanced wearable devices for the wireless body area network.

Acknowledgment - We thank the laboratory members for their helpful advice and guidance in writing the essay. Thanks to Rohde \& Schwarz for providing the test environment to assist with the antenna measurements. This work is supported by the National Natural Science Foundation of China, project No. 61571320.

\section{References}

[1] Iто K., Lin H.Y., Lin C.H., Novel small antennas for body-centric wireless communications, [In] 2012 Asia Pacific Microwave Conference Proceedings, IEEE, Kaohsiung, Taiwan, December 4-7, 2012, pp. 424-426, DOI: 10.1109/APMC.2012.6421619.

[2] TAHIR F.A., JAVED A., A compact dual-band frequency-reconfigurable textile antenna for wearable applications, Microwave and Optical Technology Letters 57(10), 2015, pp. 2251-2257, DOI: 10.1002/ mop.29311.

[3] Hao Y., Alomainy A., Hall P.S., Nechayev Y.I., Parini C.G., Constantinou C.C., Antennas and propagation for body centric wireless communications, [In] IEEE/ACES International Conference on Wireless Communications and Applied Computational Electromagnetics, IEEE, Honolulu, HI, USA, April 3-7, 2005, pp. 1-7, DOI: 10.1109/WCACEM.2005.1469656.

[4] RaAd H.R., Abbosh A.I., Al-Rizzo H.M., Rucker D.G., Flexible and compact AMC based antenna for telemedicine applications, IEEE Transactions on Antennas and Propagation 61(2), 2013, pp. 524-531, DOI: 10.1109/TAP.2012.2223449.

[5] Song L., Myers A.C., Adams J.J., Zhu Y., Stretchable and reversibly deformable radio frequency antennas based on silver nanowires, ACS Applied Materials \& Interfaces 6(6), 2014, pp. 4248-4253, DOI: 10.1021/am405972e.

[6] Rai T., Dantes P., Bahreyni B., Kim W.S., A stretchable RF antenna with silver nanowires, IEEE Electron Device Letters 34(4), 2013, pp. 544-546, DOI: 10.1109/LED.2013.2245626.

[7] Llatser I., Kremers C., Cabellos-Aparicio A., Jornet J.M., Alarcón E., Chigrin D.N., Graphene -based nano-patch antenna for terahertz radiation, Photonics and Nanostructures: Fundamentals and Applications 10(4), 2012, pp. 353-358, DOI: 10.1016/j.photonics.2012.05.011.

[8] Guo X., Huang Y., Zhao Y., Mao L., Gao L., Pan W., Zhang Y., Liu P., Highly stretchable strain sensor based on SWCNTS/CB synergistic conductive network for wearable human-activity monitoring and recognition, Smart Materials and Structures 26(9), 2017, article 095017, DOI: 10.1088/1361-665X/ aa79c3. 
[9] Hassan A., Ali S., Hassan G., Bae J., Lee C.H., Inkjet-printed antenna on thin PET substrate for dual band Wi-Fi communications, Microsystem Technologies 23(8), 2017, pp. 3701-3709, DOI: $10.1007 / \mathrm{s} 00542-016-3113-\mathrm{y}$.

[10] Huang G.W., XIAo H.M., Fu S.Y., Wearable electronics of silver-nanowire/poly(dimethylsiloxane) nanocomposite for smart clothing, Scientific Reports 5, 2015, article 13971, DOI: 10.1038/srep13971.

[11] Qiu Y., Jung Y.H., Lee S., Shin T.Y., Lee J., Xu Y.H., Xu R., Lin W., Behdad N., Ma Z., Compact parylene-c-coated flexible antenna for WLAN and upper-band UWB applications, Electronics Letters 5(24), 2014, pp. 1782-1784.

[12] Chang Min Lee, Youngsung Kim, Yonguin Kim, Il Kwon Kim, Chang Won Jung, A flexible and transparent antenna on a polyamide substrate for laptop computers, Microwave and Optical Technology Letters 57(5), 2015, pp. 1038-1042, DOI: 10.1002/mop.29011.

[13] Whittow W.G., Chauraya A., Vardaxoglou J.C., Li Y., Torah R., Yang K., Beeby S., Tudor J., Inkjet-printed microstrip patch antennas realized on textile for wearable applications, IEEE Antennas and Wireless Propagation Letters 13, 2014, pp. 71-74, DOI: 10.1109/LAWP.2013.2295942.

[14] Sнiм B.S., Chen W., Doty C., Xu C.L., Kotov N.A., Smart electronic yarns and wearable fabrics for human biomonitoring made by carbon nanotube coating with polyelectrolytes, Nano Letters 8(12), December 2008, pp. 4151-4157, DOI: 10.1021/n1801495p.

[15] Qu S.W., RuAn C., Wang B.Z., Bandwidth enhancement of wide-slot antenna fed by CPW and microstrip line, IEEE Antennas and Wireless Propagation Letters 5, 2006, pp. 15-17, DOI: 10.1109/ LAWP.2005.863616.

[16] Chair R., Kishk A.A., LeE K.F., Smith C.E., Kajfez D., Microstrip line and CPW FED ultra wideband slot antennas with $U$-shaped tuning stub and reflector, Progress in Electromagnetics Research, PIER 56, 2006, pp. 163-182, DOI: 10.2528/PIER05060701.

Received January 2, 2020 in revised form May 19, 2020 